\title{
Crosstalk Between the Heart and Blood in Heart Failure
}

\author{
Naoki Sato, MD, PhD
}

I n 1628, William Harvey published "Exercitatio Anatomica de Motu Cordis et Sanguinis in Animalibus", in which he described systemic blood circulation being pumped to the organs by the heart. ${ }^{1}$ Based on his discovery, the relationship between the heart and blood was found to be important for understanding the pathophysiology of heart failure (HF). The heart beats approximately 100,000 beats per day and pumps blood to organs. An abnormality in any component of the blood results in a blood circulation disorder. Bone marrow dysfunction also affects the blood circulation and the heart. Bone marrow generates hundreds of billions of new blood cells every day. It contains hematopoietic stem cells and mesenchymal stem cells. Hematopoietic stem cells produce myeloid stem cells, which develop into red blood cells, platelets, and white blood cells, and lymphoid stem cells, which develop into lymphocytes. In contrast, mesenchymal stem cells are multipotent ${ }^{2}$ and can differentiate into cardiomyocytes. ${ }^{3}$ Therefore, bone marrow has important roles in terms of cell generation, as well as circulation, hemodynamics, and immunological

\begin{tabular}{l} 
Article p576 \\
\hline status in HF. \\
In this issue of the Journal, Yamaguchi et al ${ }^{4}$ demonstrate \\
that a low platelet count was associated with a poor \\
outcome in patients with acute HF. Their study was single- \\
center, retrospective and observational, with several \\
limitations. However, it sheds important light on the \\
pathophysiology of HF from the viewpoint of the rela- \\
tionship between the heart and blood. However, the \\
relationship between platelet count and outcome has not \\
been shown in previous studies that have clarified the \\
relationship between platelet volume, but not platelet count, \\
and outcome in acute HF.5 These differences might be \\
related to etiological factors of HF (i.e., ischemic or non- \\
ischemic, medications, and comorbidities, such as diabetes \\
mellitus, dyslipidemia, and hypertension). Fundamentally, \\
activated platelets could be related to a poor outcome. One \\
of the markers of activation of platelet function is platelet
\end{tabular}

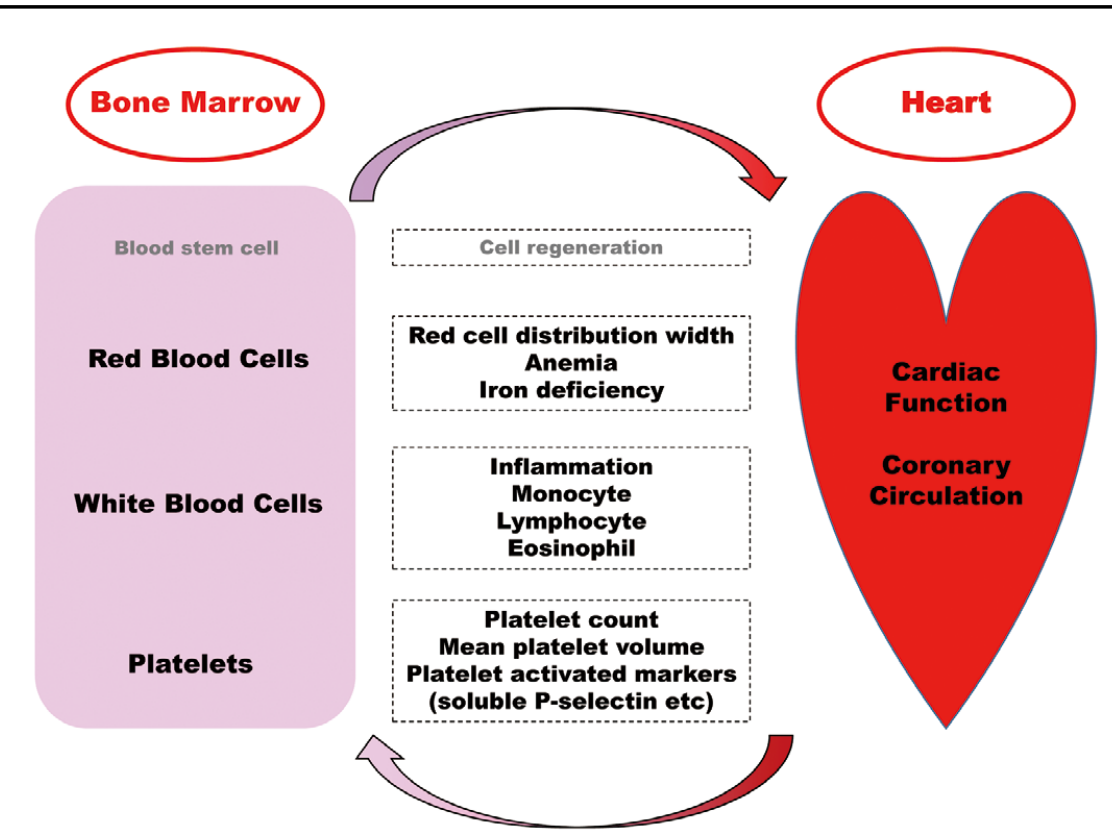

Figure. Crosstalk between the heart and blood.

The opinions expressed in this article are not necessarily those of the editors or of the Japanese Circulation Society.

Received January 10, 2019; accepted January 16, 2019; J-STAGE Advance Publication released online January 30, 2019

Cardiology and Intensive Care Unit, Nippon Medical School, Musashi-Kosugi Hospital, Kawasaki, Japan

Mailing address: Naoki Sato, MD, PhD, Cardiology and Intensive Care Unit, Nippon Medical School, Musashi-Kosugi Hospital, 1-396 Kosugi-cho, Nakahara-ku, Kawasaki 211-8533, Japan. E-mail: nms-ns@nms.ac.jp

ISSN-1346-9843 All rights are reserved to the Japanese Circulation Society. For permissions, please e-mail: cj@j-circ.or.jp 
count, and platelet volume could be another marker of activated platelets because an increased volume of platelets correlates with rapid aggregation and increased production of thromboxane B2, serotonin, $\beta$-thromboglobin, glycoproteins, and $\mathrm{P}$-selectin. ${ }^{5-9}$ These activated platelet-related changes occur in acute $\mathrm{HF}$, but not in chronic $\mathrm{HF}^{8}$

Activation of the sympathetic nervous system increases plasma norepinephrine concentrations, which causes activation of platelets and the coagulation system, and is related to outcome in acute $\mathrm{HF}$. The increase in plasma epinephrine levels by an activated sympathetic nervous system also induces platelet aggregation and damage to the vessel wall. Furthermore, the renin-angiotensin-aldosterone system (RAAS) is activated and angiotensin II levels are elevated in severe HF. ${ }^{10}$ Angiotensin II increases platelet aggregation. This could be caused in part by a thrombininduced, dose-dependent elevation of intraplatelet free calcium levels and it could enhance hemostatic abnormalities. ${ }^{10}$ Therefore, enhanced neurohumoral systems in $\mathrm{HF}$ are related to activation of platelets and hemostatic abnormalities, as well as to poor outcome.

In $\mathrm{HF}$ with reduced left ventricular ejection fraction (HFrEF), inhibition of the RAAS and sympathetic nervous system is recommended for improvement of symptoms. ${ }^{\mathbf{1 1}}$ Guideline-directed medical therapy (GDMT) improves outcome in HFrEF because it improves cardiac and vascular function, and consequently improves outcomes. ${ }^{10}$ However, GDMT cannot prevent worsening of HFrEF or improve the outcome for all patients with $\mathrm{HFrEF}$. There are several reasons why GDMT does not work well for some patients with HFrEF. The most important reason is inappropriate modification of the activated sympathetic nervous system and RAAS. Another reason is that hematological abnormalities, including activated platelets, have not been well reported. This hematological mechanism should be considered, especially in patients with HFrEF who cannot tolerate GDMT. This is because some $\beta$-blockers ${ }^{12}$ or reninangiotensin inhibitors ${ }^{\mathbf{1 3}, \mathbf{1 4}}$ can reduce platelet aggregation. Non-selective lipophilic $\beta$-blockers stabilize the platelet cell membrane and block $\beta_{2}$-receptors of platelets, resulting in a decrease in intraplatelet calcium availability. Subsequently, these effects reduce platelet aggregation. ${ }^{12}$ Angiotensinconverting enzyme inhibitors ${ }^{\mathbf{1 3}}$ or angiotensin II receptor blockers ${ }^{\mathbf{1 3}}$ also decrease platelet activation. Possible mechanisms for inhibiting activated platelets by angiotensin II receptor blockers are inhibition of cyclooxygenase 2 and platelet adhesion/agglutination stimulated by nitric oxide. ${ }^{14}$ Furthermore, both of these drugs can reduce plasma catecholamine levels by improving inappropriate activation of the sympathetic nervous system and RAAS, and can consequently decrease platelet activation.

Therefore, crosstalk between the heart and blood in HF, especially in acute HF, should be considered to understand the pathophysiology of HF (Figure). This viewpoint might shed light on the development of novel approaches to improving the outcome of $\mathrm{HF}$.

\section{Disclosures}

None.

\section{References}

1. Harvey W. Exercitatio Anatomica de Motu Cordis et Sanguinis in Animalibus. Frankfurt: William Fitzer, 1628.

2. Pittenger MF, Mackay AM, Beck SC, Jaiswal RK, Douglas R, Mosca JD, et al. Multilineage potential of adult human mesenchymal stem cells. Science 1999; 284: 143-147.

3. Toma C, Pittenger MF, Cahill KS, Byrne BJ, Kessler PD. Human mesenchymal stem cells differentiate to a cardiomyocyte phenotype in the adult murine heart. Circulation 2002; 105: 93-98.

4. Yamaguchi S, Abe M, Arakaki T, Arasaki O, Shimabukuro M. Incremental prognostic value of platelet count in patients with acute heart failure: A retrospective observational study. Circ J 2019; 83: 576-583.

5. Kandis H, Ozhan H, Ordu S, Erden I, Caglar O, Basar C, et al. The prognostic value of mean platelet volume in decompensated heart failure. Emerg Med J 2011; 28: 575-578.

6. Jacob J, Martín-Sánchez FJ, Gil V, Llorens P. The prognostic usefulness of platelets in acute heart failure. Emerg Med J 2011; 28: 1079.

7. Bath PM, Butterworth RJ. Platelet size: Measurement, physiology and vascular disease. Blood Coag Fibrinol 1996; 7: 157-161.

8. Chung I, Choudhury A, Lip GY. Platelet activation in acute, decompensated congestive heart failure. Thromb Res 2007; 120: $709-713$.

9. Jafri SM, Ozawa T, Mammen E, Levine TB, Johnson C, Goldstein S. Platelet function, thrombin and fibrinolytic activity in patients with heart failure. Eur Heart J 1993; 14: 205-212.

10. Sbarouni E, Bradshaw A, Andreotti F, Tuddenham E, Oakley $\mathrm{CM}$, Cleland JG. Relationship between hemostatic abnormalities and neuroendocrine activity in heart failure. Am Heart J 1994; 127: $607-612$.

11. Goldgrab D, Balakumaran K, Kim MJ, Tabtabai SR. Updates in heart failure 30-day readmission prevention. Heart Fail Rev, doi:10.1007/s10741-018-9754-4.

12. Bonten T. Effect of $\beta$-blockers on platelet aggregation: A systematic review and meta-analysis. Br J Clin Pharmacol 2014; 78: $940-$ 949.

13. Gibbs CR, Blann AD, Watson RD, Lip GY. Abnormalities of hemorheological, endothelial, and platelet function in patients with chronic heart failure in sinus rhythm: Effects of angiotensinconverting enzyme inhibitor and $\beta$-blocker therapy. Circulation 2001; 103: 1746-1751.

14. Yamada K, Hirayama T, Hasegawa Y. Antiplatelet effect of losartan and telmisartan in patients with ischemic stroke. $J$ Stroke Cerebrovasc Dis 2007; 16: 225-231. 